\title{
Thermal Stability of Epoxy Nanocomposites: Surface Treatment and Morphology Impact Based on $\mathrm{Nano} \mathrm{SiO}_{2}$ and hBN Fillers
}

\author{
Dayuan Qiang $^{1,2}$, Xinyu Wang ${ }^{1,2}$, Yan Wang ${ }^{3}$, Thomas Andritsch ${ }^{1,2}$ and George \\ Chen $^{1,2}$ \\ ${ }^{1}$ School of Electronic and Computer Science, University of Southampton, Southampton, United \\ Kingdom \\ ${ }^{2}$ The Tony Davies High Voltage Laboratory, University of Southampton, Southampton, United \\ Kingdom \\ ${ }^{3}$ Complex lab, College of Computer Science and Engineering, University of Electronics Science and \\ Technology of China, Chengdu, China
}

E-mail: opstraxex@gmail.com

Received xxxxxx

Accepted for publication $\mathrm{xxxxxx}$

Published xxxxxx

\begin{abstract}
Epoxy resin is one of the most commonly used thermosetting macromolecular synthetic materials. It displays excellent adhesiveness properties, good dielectric property, mechanical property and chemical stability. Consequently, epoxy resins have been widely used for many industrial purposes, such as electrical casting into power transformers, ignition coil systems and potting. In this paper, TGA and DSC measurements were carried out to evaluate the thermal stability of epoxy nanocomposites. Based on the results of dispersion and distribution of particles within epoxy nanocomposites, it concluded that both presences of nano $\mathrm{SiO}_{2}$ and hexagonal $\mathrm{BN}(\mathrm{hBN})$ particles have obvious impact on base materials in which the influences of latter particle are much more significant due to its shape, and thus both fillers leads to worse thermal stability than pure samples. However, particles could act as flame retardants in polymer nanocomposites and postpone the initiation of decomposition by hindering/slowing the oxidisation. When compared within two $\mathrm{SiO}_{2}$ based nanocomposites, the surface treatment seems to help mitigate the influences on base materials by achieving better filler dispersion and modify the cross-linking density at the interfacial areas by removing surface functional groups.
\end{abstract}

Keywords: thermal stability, epoxy nanocomposites, silica, boron nitride, surface treatment, morphology

\section{Introduction}

Epoxy resin generally refers to epoxy polymers containing two or more epoxy groups and is one of the most commonly used thermosetting macromolecular synthetic materials. Since containing reactive epoxy groups, it can react with many curing agents/hardeners and form three dimensional cross- linking network structures. Epoxy resins show excellent adhesiveness properties, good dielectric property, mechanical property and chemical stability [1]. Because of its advantages, such as low cost and easy shaping, epoxy resins have now widely used and becomes the essential materials for some industrial applications including as insulators [2]. As some applications (e.g., power transformers and potting) require higher thermal stability/conductivity than others [3], with 
expecting better performance and broader usage demand, it is challenging to meet the growing requirements and much research has been carried out to look for new methods for modification, including adding nano-fillers to produce nanocomposites (NCs) which is one of the most promising ones [4].

Previous research has intensively studied nano-clay based nanocomposites and concluded thermal stability was improved due to the presence of nano-clay in bulk by TGA measurement [5, 6]. Kumar et al. then reviewed most introduced nano-particulates and degradation and stability of resultant nanocomposites. They concluded the presence of nano-fillers undoubtedly enhanced the thermal properties and it was worth doing further studies [7]. Tarrío-Saavedra et al. studied the effect of fumed silica on thermal stability of epoxy composites by using three temperature indexes (initial decomposition temperature, maximum rate loss temperature and integral procedure decomposition temperature) in TGA measurement, and finally concluded introduced particles would act as flame retardants to protect the matrix from thermal degradation [8]. However, fillers also led to the low cross-linking density of epoxy nanocomposites and resulted in worse thermal stability. Moreover, they also pointed out the presence of hydroxyl groups on $\mathrm{SiO}_{2}$ surface affected and led to worse thermal properties as well. Luo et al. introduced an interface designed epoxy nanocomposite systems filled with microcrystalline cellulose fibers (MCFs) [9], in which NCs showed enhanced thermal stability as a consequence of improved cross-linking density and glass transition temperature $\left(T_{\mathrm{g}}\right)$. Their work proved the strong interfacial interactions could significantly improve the thermal stability of epoxy $\mathrm{NC}$ systems. Boron nitride (BN) acting as modification fillers has also attracted numbers of research [1012]. BN based nanocomposites showed an increase in thermal conductivity due to the presence of BN fillers $[10,11] . Y u$ et al. investigated effects of interfacial modification on thermal properties of boron nitride (BN) nanoplatelets based epoxy nanocomposites [12]. They found surface treatment could improve the thermal properties of nanocomposites.

However, the influences of surface treatment on thermal properties of $\mathrm{SiO}_{2}$ filled epoxy NCs and thermal stability of epoxy hBN NCs still lack relatively in-depth research. Therefore, the goal of this paper is, first, to investigate how surface treatment to remove hydroxyl groups on the particle surface would affect thermal properties of epoxy nano- $\mathrm{SiO}_{2}$ based composites. Second, based on TGA and DSC measurements which are usually solely applied in former studies, an overall and comprehensive understanding how the resulting structures due to the presence of nano-fillers can be given according to the morphology analysis. Last, as $\mathrm{SiO}_{2}$ and $\mathrm{hBN}$ particles are in different shapes, it is also important to investigate how this will influence the morphology of epoxy nanocomposites and further relate to their thermal properties.

\section{Experiment Preparation}

\subsection{Materials}

The testing samples were prepared based on bisphenol-A diglycidyl ether (D.E.R. 332, density $1.16 \mathrm{~g} \cdot \mathrm{cm}^{-3}$ ) along with polyether amine hardener (Jeffamine D-230, density 0.948 $\mathrm{g} \cdot \mathrm{cm}^{-3}$ ) supplied by Huntsman. The fillers used in the study are commercially available untreated $\mathrm{SiO}_{2}$ and $\mathrm{BN}$ fillers provided by Sigma-Aldrich and Momentive respectively. More information is detailed and listed in Table 1. Moreover, trimethoxy (octyl) silane was used as a coupling agent to produce $\mathrm{C} 8$-treated nano $\mathrm{SiO}_{2}$ in order to eliminate the hydroxyl groups on the surface of $\mathrm{SiO}_{2}$ particles and form relatively hydrophobic and unfunctional surface structures (same preparation method was introduced in [13]). The success of modification has also been proved by TGA as shown in Fig. 1 in which surface-treated $\mathrm{SiO}_{2}$ shows one more weight-loss stage than the untreated ones. In the process of sample preparation, epoxy and its nanocomposites were cured at $120^{\circ} \mathrm{C}$ for 4 hours with the ratio between epoxy resin and hardener was 1000:344 [14]. Filler loading ratios of nanoparticles are $0.5,1,3$ and $5 \mathrm{wt} \%$, and following abbreviations are used while coding the samples: EP for epoxy resin, $\mathbf{S}$ for untreated nano-silica composites, $\mathbf{S T}$ for treated silica, $\mathbf{B}$ for boron nitride and the number represents the filler loading. For example, EPS1 represents epoxy nanocomposites loaded with $1 \mathrm{wt} \%$ untreated silica.

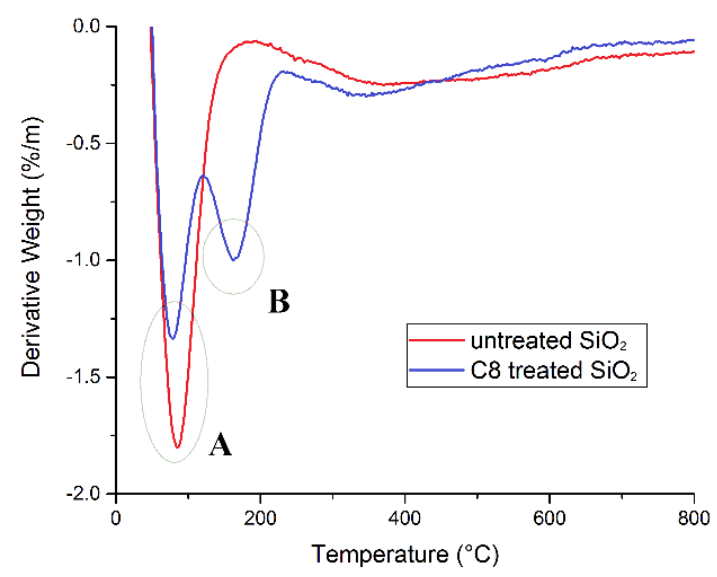

FIG. 1. TGA derivative result of untreated and C8-treated $\mathrm{SiO}_{2}$ particles with dichloromethane (DCM). Reproduced by permission of the Institution of Engineering \& Technology from ref [15].

Table 1. Particle information

\begin{tabular}{cccc}
\hline Type & Size $(\mathrm{nm})$ & Structure & Shape \\
\hline $\mathrm{SiO}_{2}$ & $10-20(\mathrm{BET})$ & Crystalline & Spherical \\
\hline & $\begin{array}{c}\text { 900(Average } \\
\text { particle size })\end{array}$ & $\begin{array}{l}\text { Hexagonal } \\
\text { crystalline }\end{array}$ & Platelets \\
& $200-500$ & & \\
& $($ Crystal Size $)$ & & \\
&
\end{tabular}




\subsection{Experiment Set-up and Characterisation Methods}

$\mathrm{EVO}^{\circledR} 50$ scanning electron microscopy (SEM) was used to characterise the morphology of epoxy and its nanocomposites. The gun voltage was set to $15 \mathrm{kV}$ with a working distance of $7-12 \mathrm{~mm}$. All samples were coated with gold before the test by the Emitech K550X sputter coater at $25 \mathrm{~mA}$ for $3 \mathrm{~min}$ for each sample.

Thermo Gravimetric Analysis (TGA) was performed on Perkin-Elmer Pyris 1 thermogravimetric analyser. Samples were weighted as same as possible with the mass of around 5 $\mathrm{mg}$ and tested by measuring the weight loss under air gas flow of $20 \mathrm{ml} \mathrm{min}{ }^{-1}$ at rate of $10{ }^{\circ} \mathrm{C} \cdot \mathrm{min}^{-1}$ from 50 to $850{ }^{\circ} \mathrm{C}$. The surface treatment of $\mathrm{SiO}_{2}$ particles was verified by TGA as well. The first peak $\mathrm{A}$ is caused by evaporation of dichloromethane (DCM), and the second peak B is believed due to loss of trimethoxy (octyl) chains on particle surfaces.

A power-compensated Perkin-Elmer DSC 7 was used with a nitrogen gas feed, controlled and finally being analyzed by Perkin-Elmer Pyris software. Samples used for testing are uniformly selected on films in each loading concentration of particles, and 5 pieces in total. The selected rate of temperature is $10{ }^{\circ} \mathrm{C} \cdot \mathrm{min}^{-1}$ for all the measurements of DSC and temperature ranges from $50{ }^{\circ} \mathrm{C}$ to $150{ }^{\circ} \mathrm{C}$.

Table 2. Sample coding and loading concentrations. Reproduced by permission of the Institution of Engineering \& Technology from ref [15].

\begin{tabular}{|c|c|c|c|}
\hline Sample Code & $\begin{array}{l}\text { Type of } \\
\text { particles }\end{array}$ & $\begin{array}{c}\text { Theoretical } \\
\text { loading } \\
\text { concentration } \\
(w t \%)\end{array}$ & $\begin{array}{c}\text { Real loading } \\
\text { concentration } \\
(w t \%)\end{array}$ \\
\hline EP0 & N/A & N/A & N/A \\
\hline EPS05 & \multirow{4}{*}{$\begin{array}{l}\text { untreated } \\
\mathrm{SiO}_{2}\end{array}$} & 0.5 & $0.751 \pm 0.090$ \\
\hline EPS1 & & 1 & $1.236 \pm 0.081$ \\
\hline EPS3 & & 3 & $2.837 \pm 0.021$ \\
\hline EPS5 & & 5 & $4.750 \pm 0.078$ \\
\hline EPST05 & \multirow{4}{*}{$\begin{array}{c}\text { C8-treated } \\
\mathrm{SiO}_{2}\end{array}$} & 0.5 & $0.634 \pm 0.096$ \\
\hline EPST1 & & 1 & $1.110 \pm 0.136$ \\
\hline EPST3 & & 3 & $2.551 \pm 0.047$ \\
\hline EPST5 & & 5 & $4.468 \pm 0.090$ \\
\hline EPB05 & \multirow{4}{*}{$\mathrm{hBN}$} & 0.5 & $0.713 \pm 0.028$ \\
\hline EPB1 & & 1 & $0.967 \pm 0.062$ \\
\hline EPB3 & & 3 & $3.211 \pm 0.038$ \\
\hline EPB5 & & 5 & $5.161 \pm 0.086$ \\
\hline
\end{tabular}

\section{Results and Analysis}

\subsection{SEM Characterisation}

The SEM images of EPS and EPST samples of $3 \mathrm{wt} \%$ and $5 \mathrm{wt} \%$ are shown in Fig. 2-5.

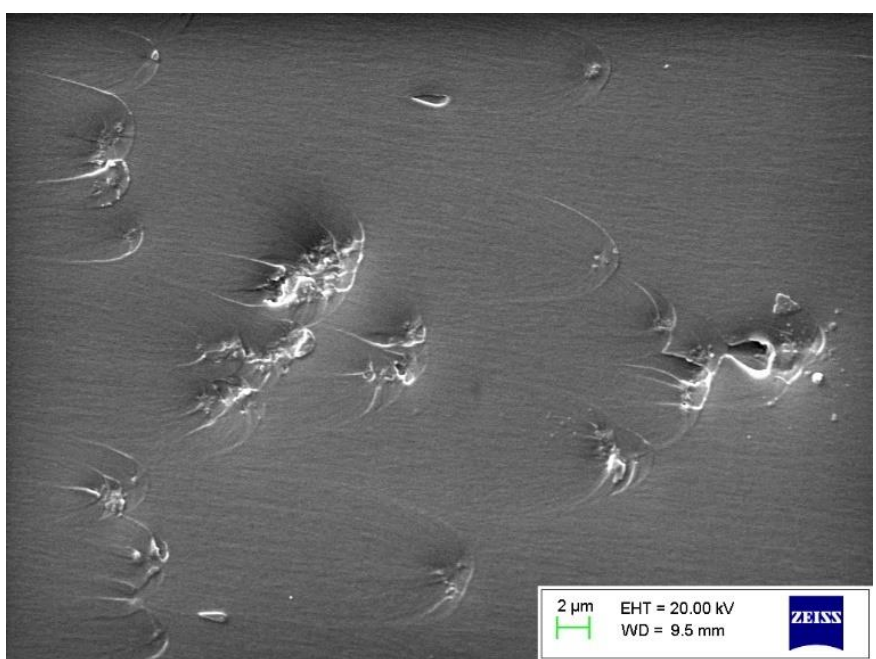

FIG. 2. SEM image of untreated $\mathrm{SiO}_{2}$ based epoxy nanocomposites, $\times 5000$, $1 \mathrm{wt} \%$.

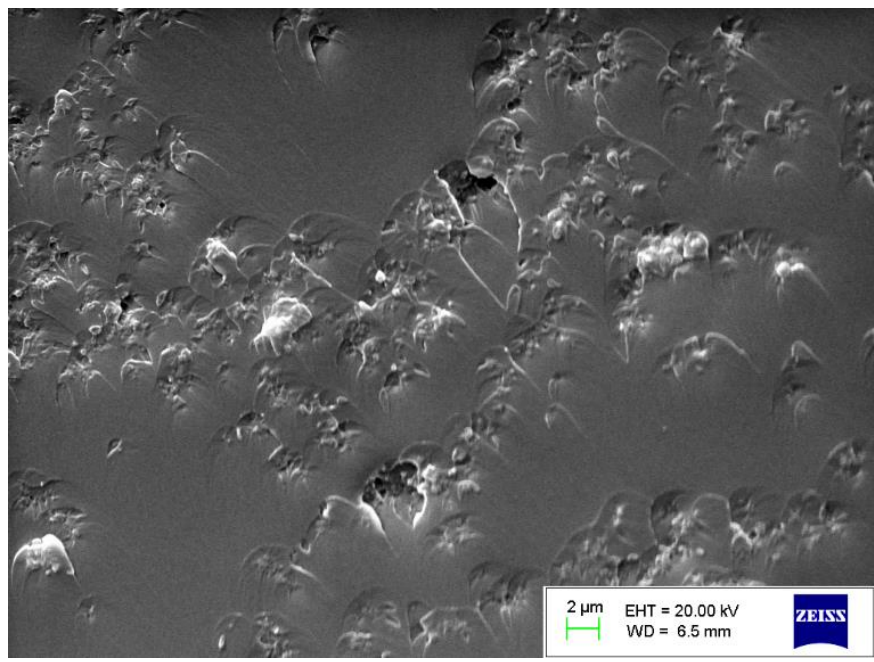

FIG. 3. SEM image of untreated $\mathrm{SiO}_{2}$ based epoxy nanocomposites, $\times 5000$, 3 wt $\%$.

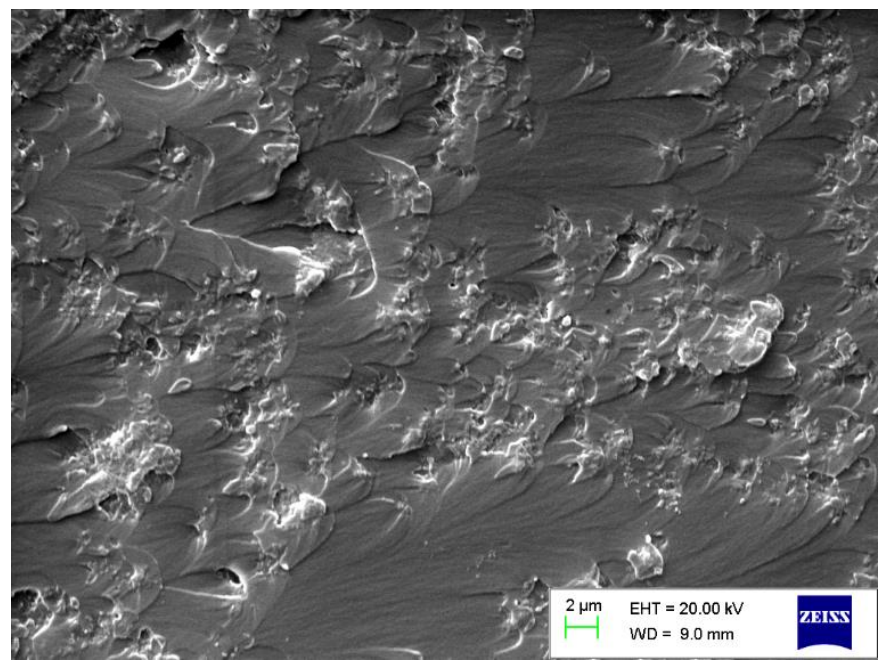

FIG. 4. SEM image of untreated $\mathrm{SiO}_{2}$ based epoxy nanocomposites, $\times 5000$, $5 \mathrm{wt} \%$. 

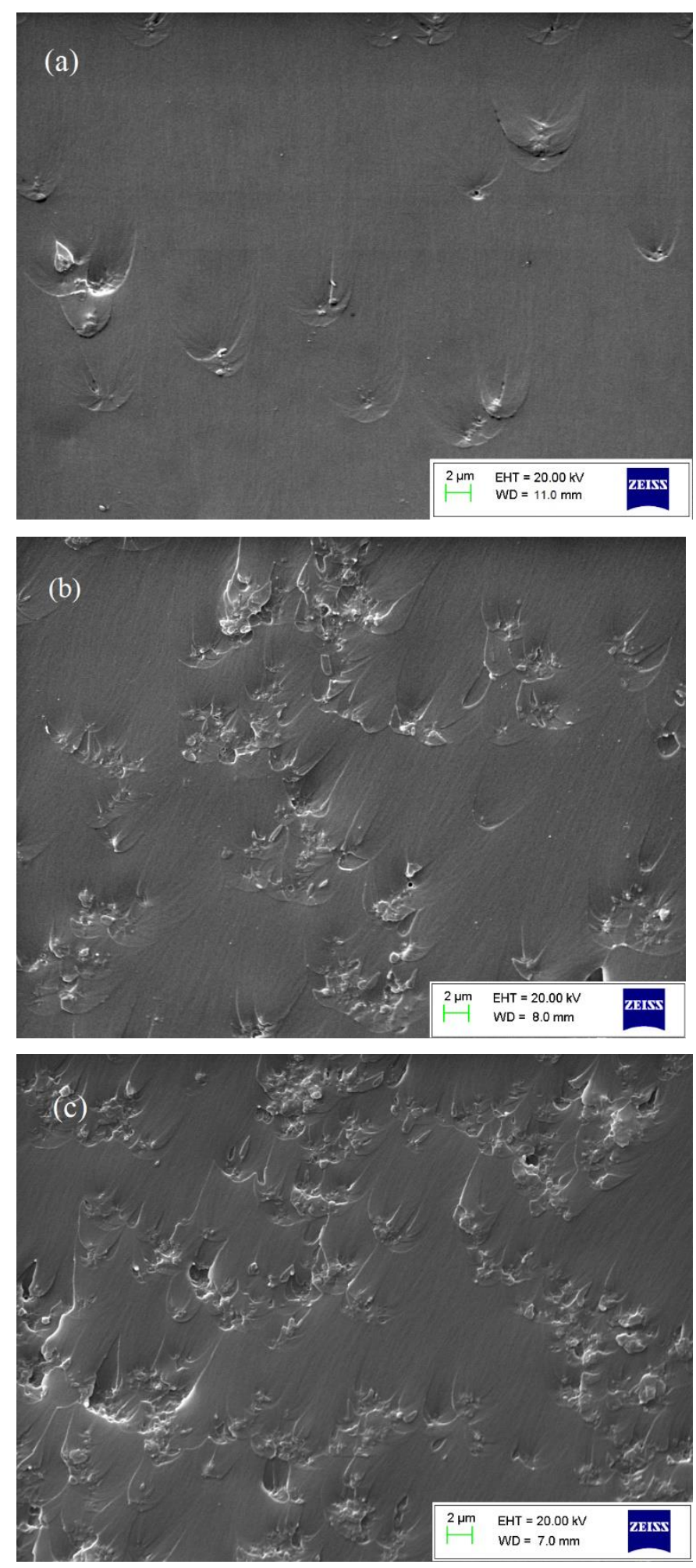

FIG. 5. SEM image of $\mathrm{C} 8$-treated $\mathrm{SiO}_{2}$ based epoxy nanocomposites, $\times 5000$ : (a) $1 \mathrm{wt} \%$; (b) $3 \mathrm{wt} \%$; (c) $5 \mathrm{wt} \%$.

It is noticed that the number of particles in EPS and EPST samples both increase with filler loading concentrations. In 3 wt\% of EPS and EPST samples, obvious agglomerations of particles/aggregates have appeared and it seems that the fillers have had a significant impact on the structure of the matrix, especially in EPS5 samples shown in Fig. 4.

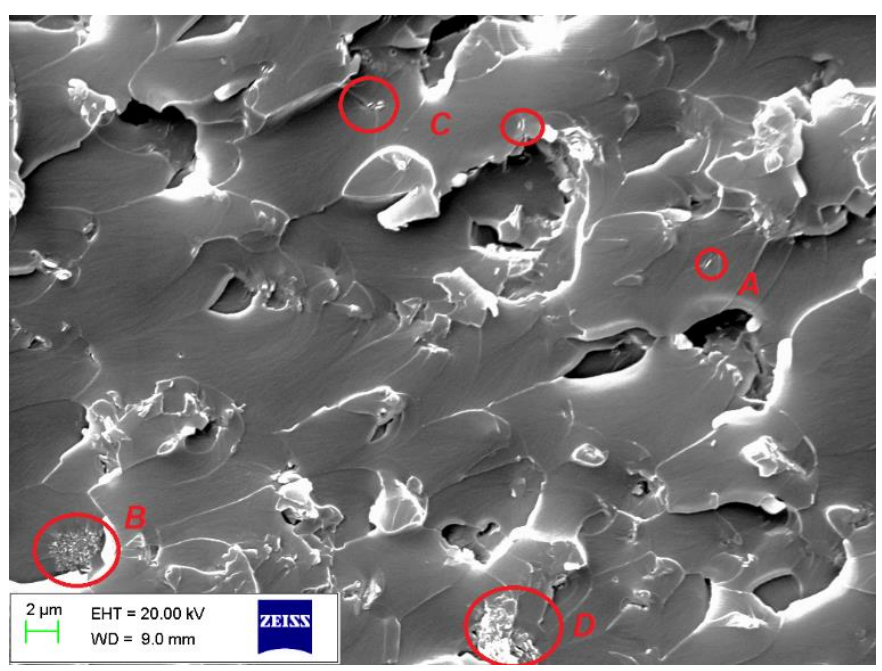

FIG. 6. SEM image of BN based epoxy nanocomposites, $\times 5000,1 \mathrm{wt} \%$.
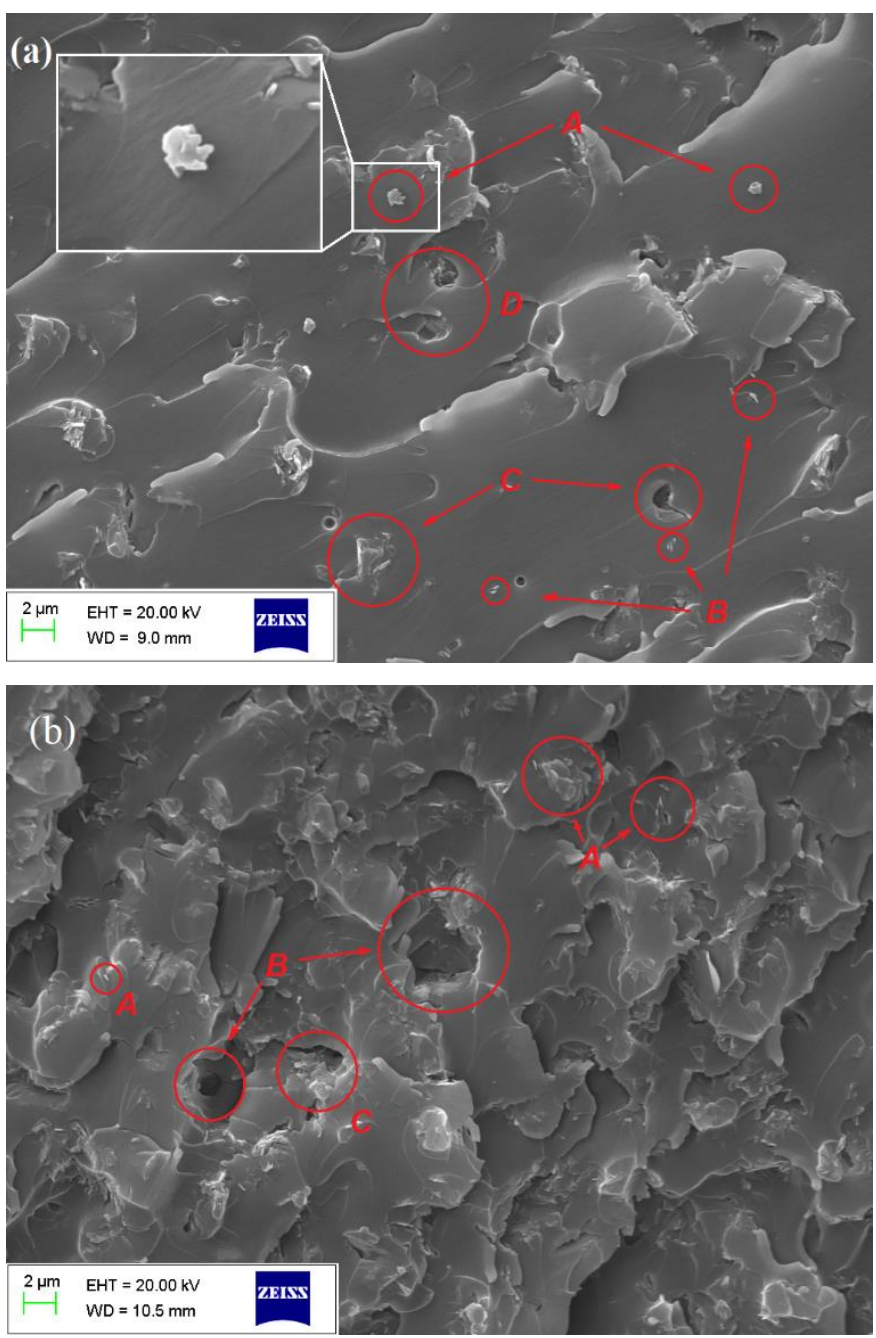

FIG. 7. SEM image of BN based epoxy nanocomposites, $\times 5000$ : (a) $1 \mathrm{wt} \%$; (b) $3 \mathrm{wt} \%$. Reproduced by permission of the Institution of Engineering \& Technology from ref [15]. 
The more significant impact on the structure of the matrix morphology may lead to deteriorated properties in epoxy nanocomposites. Comparing EPS and EPST samples, it is easy to note that the surface treatment acts to reduce disturbance of the polymer matrix, this is especially clear for high filler concentrations of $\mathrm{SiO}_{2}$ samples. EPST3 and EPST5 samples seem to show relatively better dispersion and distribution (shown in Fig. 5).
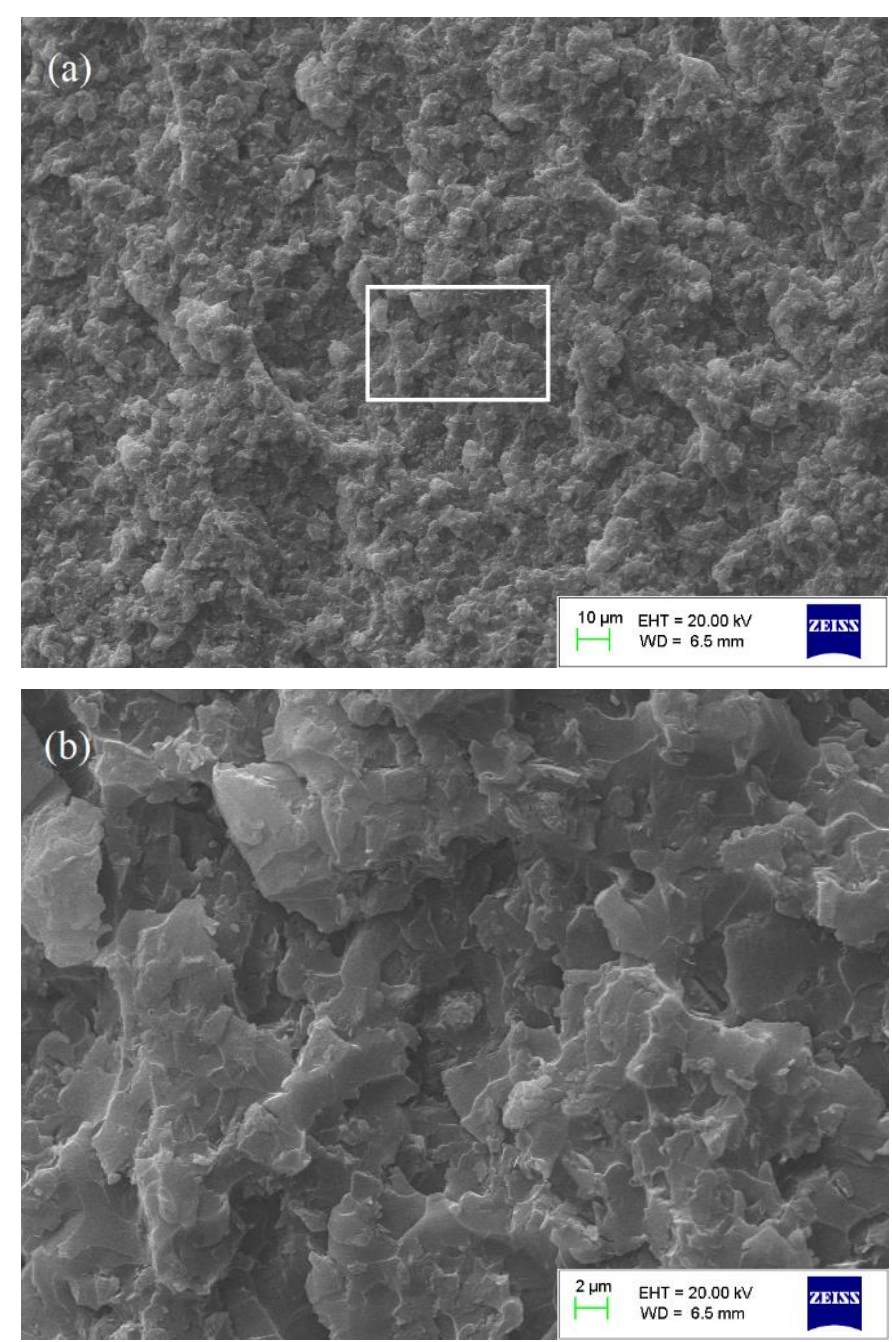

FIG. 8. SEM image of BN based epoxy nanocomposites, $\times 5000,5 \mathrm{wt} \%$ : (a) $\times 1000$; (b) Zooming into the square area in (a).

The SEM images of EPB samples are shown in Fig. 6-9. For this type of nanoparticles it can be concluded there are three distinct forms, which have also been observed in clay platelet-based nanocomposites [7]: First, due to the sonication process, particles can be exfoliated and solely dispersed in the matrix as shown in Circle A of Fig. 6 and Fig. 7(b), or loosely agglomerate together (see in Circle $B$ of Fig. 6). Second, particles are also agglomerated as sphere-like aggregates as shown in Circle A of Fig. 7(a) and in the high magnification insets within Fig. 9. Third, some exfoliated particle plates could intercalate with the chains or their segments [7] as shown in Circle $C$ of Fig. 6 and Circle B of Fig. 7(a) and
Circles in Fig. 9. Moreover, the presence of hBN particles could lead to some stress concentration sites and initiation of cracks [16]. This type of feature is shown in Circle D of Fig. 7(a) and Circle B of Fig. 7(b). The cracking and disruption of the matrix become more severe in samples of higher filler loading. It is obvious that $\mathrm{hBN}$ particles have a much more noticeable impact on the morphology of base material than $\mathrm{SiO}_{2}$ nanoparticles and tend to produce a layered structure in the matrix as shown Circle D of Fig. 6, Circle C of Fig. 7(b) and Fig. 8, and become more obvious with an increase of filler loadings.

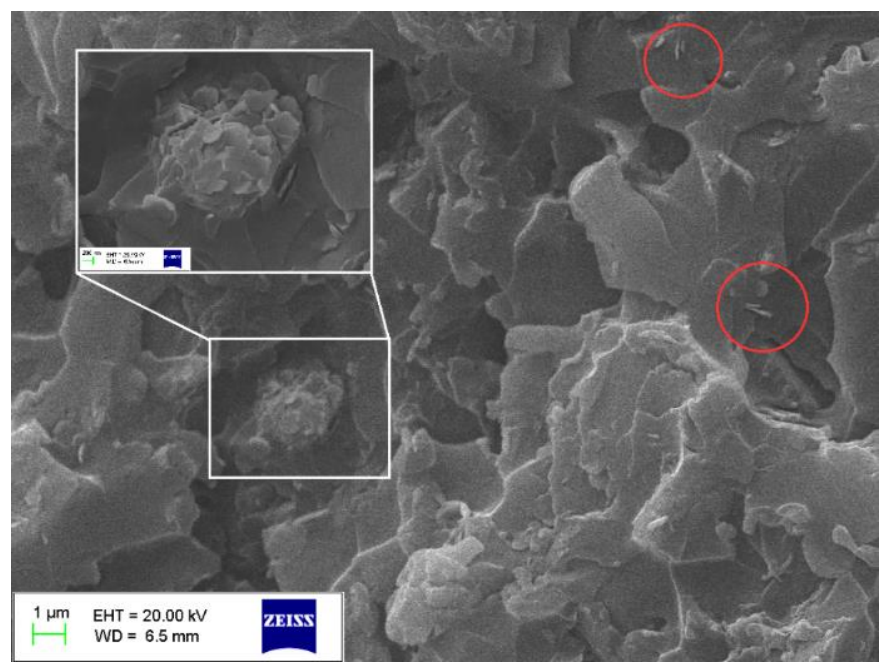

FIG. 9. SEM image of BN based epoxy nanocomposites, $\times 10000,5 \mathrm{wt} \%$, (inset, $\times 50000)$.

\subsection{TGA Experiment}

The purpose of the study in this section is to investigate the influence of nanoparticles on the thermal stability of epoxy composites. Normally, two temperature indexes are used to clarify the thermal stability: one is initial decomposition temperature (IDT) $\mathrm{T}_{I D T}$ which indicates the $5 \%$ weight loss of total mass, another is the maximum rate loss temperature $\mathrm{T}_{\max }$ $[5,8,17]$. Those most representative results of EP0, EPS, EPST and EPB samples are shown in Fig. 10-12 and Fig. 14-16. In addition, two indexes are concluded in Table 3 and compared in Fig. 13 and Fig. 17.

As shown in Fig. 10 and 11, the initial decomposition temperature in EPS and EPST samples increase when compared to EP0, which is reportedly due to the filled silica restricting the mobility of polymer chains and acting as flame retardants for polymers $[8,18,19]$. The filled silica particles near the surface would form a layer to protect the materials from oxidizing $[8,20]$. For EPS, there is a lower value in $0.5 \mathrm{wt} \%$ samples than the EP0 and may result from a lower cross-linking degree [21].

With the increase in filler loadings, the surface protective effect becomes dominant again. EPST shows similar increasing trends of $\mathrm{T}_{I D T}$, however, results in most filler 
loadings are higher than the EPS samples. This phenomenon may be caused by the hydroxyl groups being left on silica particles in EPS samples that will lead to the formation of hydrogen bonds, then low cross-linking density at the interface and further lowering the $\mathrm{T}_{I D T}$.
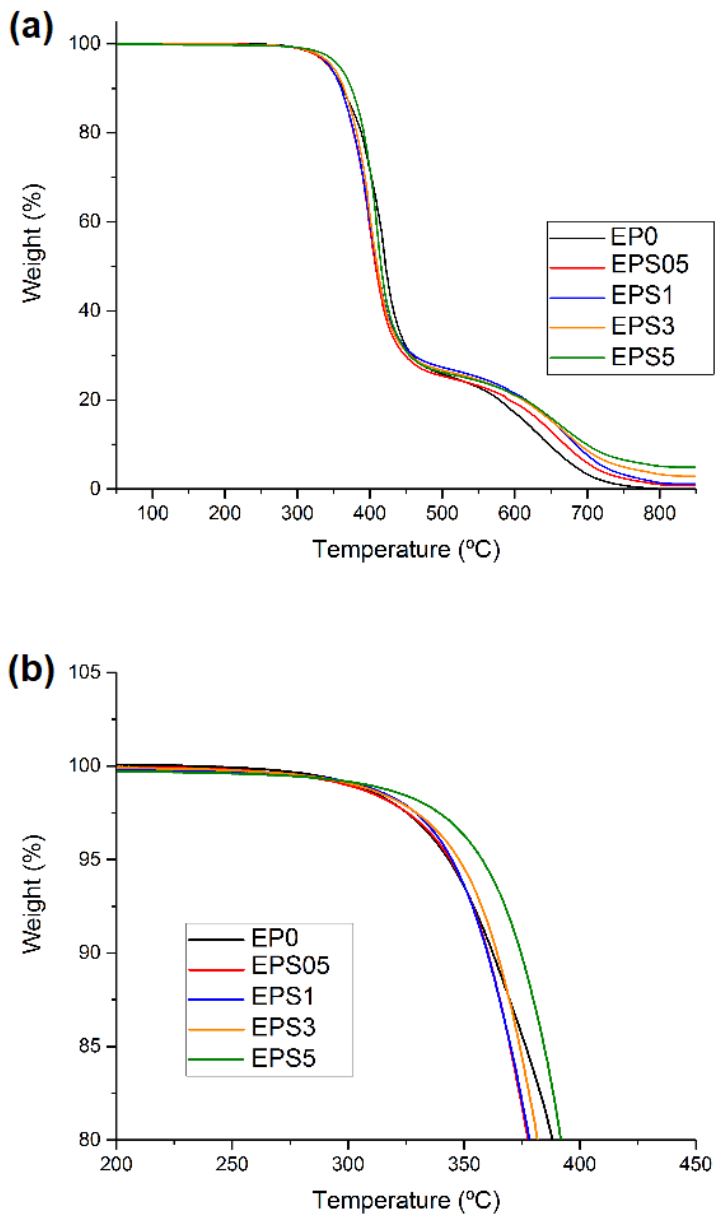

FIG. 10. TGA traces of EP0 and EPS: (a) whole; (b) zooming in to initial decomposition temperature range.

In EPB samples, as mentioned in section 3.1, hBN particles could have a significant impact on the base material and lead to very low curing density. Such low curing density will create large numbers of short chains. As short chains are more thermally stable than longer ones which should exist more in EPS and EPST, $\mathrm{T}_{I D T}$ of EPB samples is higher than that of silica nanocomposites at 0.5 and $1 \mathrm{wt} \%$ and EP0. However, $\mathrm{T}_{I D T}$ of EPB decreases with the growth of filler loadings. This should be due to the much higher thermal conductivity of hBN when compared to silica particles as shown in Fig. 13, which are 20-400 $\mathrm{W} \cdot \mathrm{m}^{-1} \mathrm{~K}^{-1}$ [22] and $1.4 \mathrm{~W} \cdot \mathrm{m}^{-1} \mathrm{~K}^{-1}$ [23]. The higher thermal conductivity of nanocomposites in high loadings results in much more thermal energy transported into bulk and enhances the decomposition of polymers, despite the protective effect of particles near the materials' surface still working.
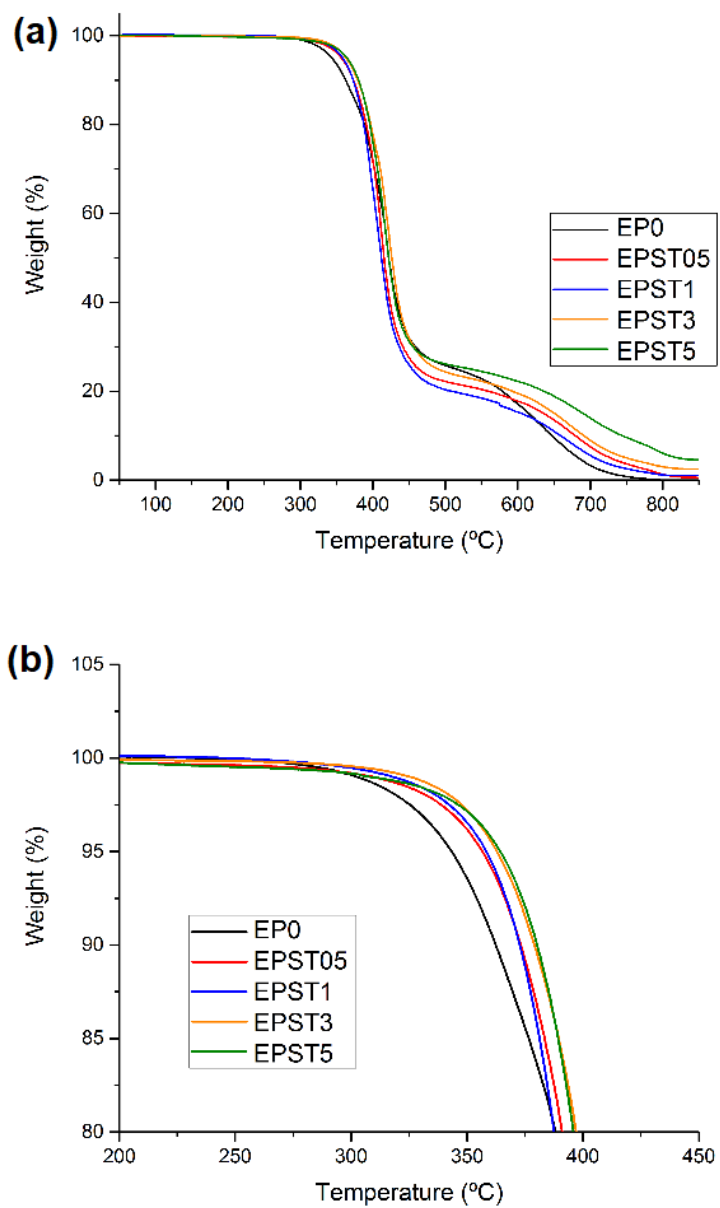

FIG. 11. TGA traces of EP0 and EPST: (a) whole; (b) zooming in to initial decomposition temperature range.

As shown in Fig. 17, because most surface protective layers have been removed due to longtime decomposition, $\mathrm{T}_{\max }$ reflects the thermal stability of composites in bulk. Owing to the lower cross-linking density resulting from adding particles, all nanocomposites show lower $\mathrm{T}_{\max }$ than EP0 $[5,8]$, whereas EPB05 shows higher value due to the higher stability of short chains. For EPS and EPST, the increasing $\mathrm{T}_{\text {max }}$ in high loadings should be caused by the formation of carbonaceoussilicate char that hinders/slows the oxidisation of bulks [6]. In addition, the difference between them shares the same mechanism in that of $\mathrm{T}_{I D T}$. Most $\mathrm{T}_{I D T}$ and $\mathrm{T}_{\max }$ results of EPB samples are little higher than EPS samples, which may indicate that the thermal stability in the high temperature of epoxy BN nanocomposites is better than untreated silica samples. However, the stability of EPB becomes worse while increasing the filler loadings. 

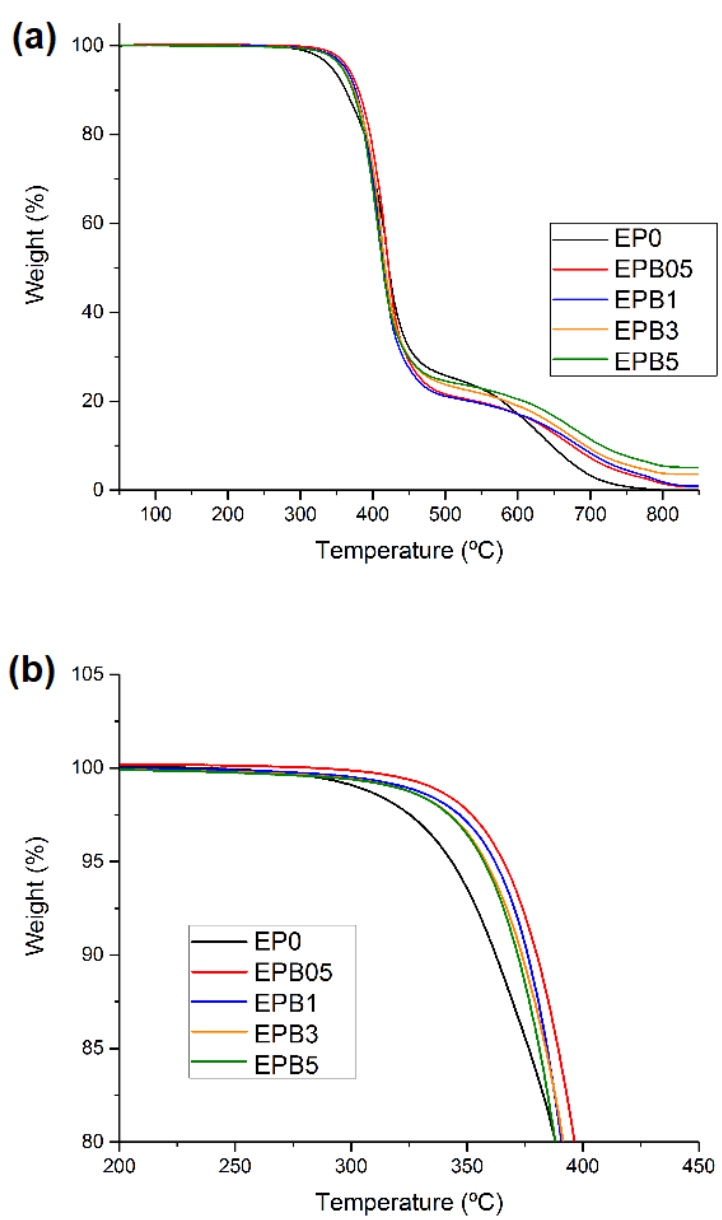

FIG. 12. TGA traces of EP0 and EPB: (a) whole; (b) zooming in to initial decomposition temperature range.

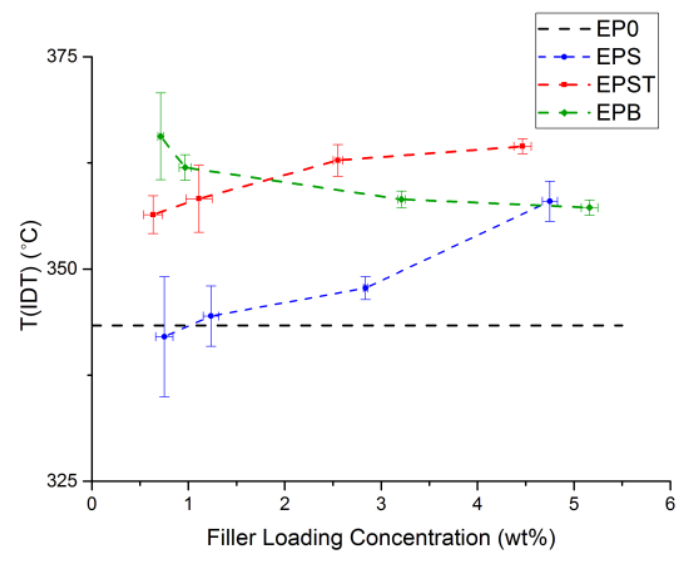

FIG. 13. Comparison of $\mathrm{T}_{\text {IDT }}$ of EP0, EPS, EPST and EPB samples in different loading concentrations.
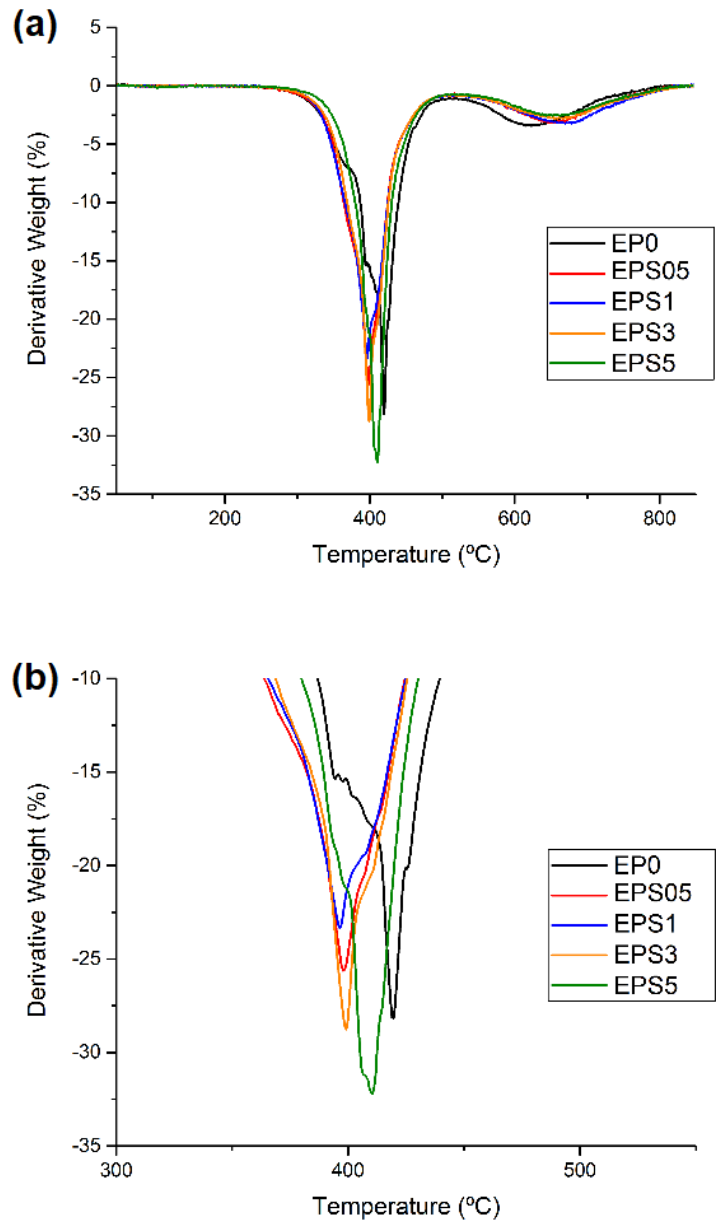

FIG. 14. Derivative traces of EP0 and EPS: (a) whole; (b) zooming in to the temperature range at the maximum rate of decomposition.

Table 3. $\mathrm{T}_{I D T}$ and $\mathrm{T}_{\max }$ of epoxy and its nanocomposites

\begin{tabular}{ccc}
\hline & & \\
Sample Code & $\mathrm{T}_{I D T}\left({ }^{\circ} \mathrm{C}\right)$ & $\mathrm{T}_{\max }\left({ }^{\circ} \mathrm{C}\right)$ \\
\hline EP0 & $343.35 \pm 2.06$ & $419.63 \pm 3.58$ \\
\hline EPS05 & $342.02 \pm 7.07$ & $397.87 \pm 3.12$ \\
EPS1 & $344.46 \pm 3.55$ & $396.51 \pm 2.77$ \\
EPS3 & $347.77 \pm 1.36$ & $399.18 \pm 2.62$ \\
EPS5 & $357.99 \pm 2.37$ & $410.55 \pm 3.27$ \\
\hline EPST05 & $356.41 \pm 2.22$ & $409.30 \pm 3.87$ \\
EPST1 & $358.28 \pm 3.95$ & $408.71 \pm 1.63$ \\
EPST3 & $362.80 \pm 1.87$ & $420.99 \pm 2.24$ \\
EPST5 & $364.45 \pm 0.87$ & $420.37 \pm 2.78$ \\
\hline EPB05 & $365.63 \pm 5.11$ & $421.31 \pm 4.35$ \\
EPB1 & $361.96 \pm 1.50$ & $417.28 \pm 1.34$ \\
EPB3 & $358.21 \pm 0.98$ & $410.27 \pm 1.44$ \\
EPB5 & $357.25 \pm 0.90$ & $406.78 \pm 1.06$ \\
\hline & & \\
\hline & & \\
\hline & & \\
\hline & & \\
\hline
\end{tabular}



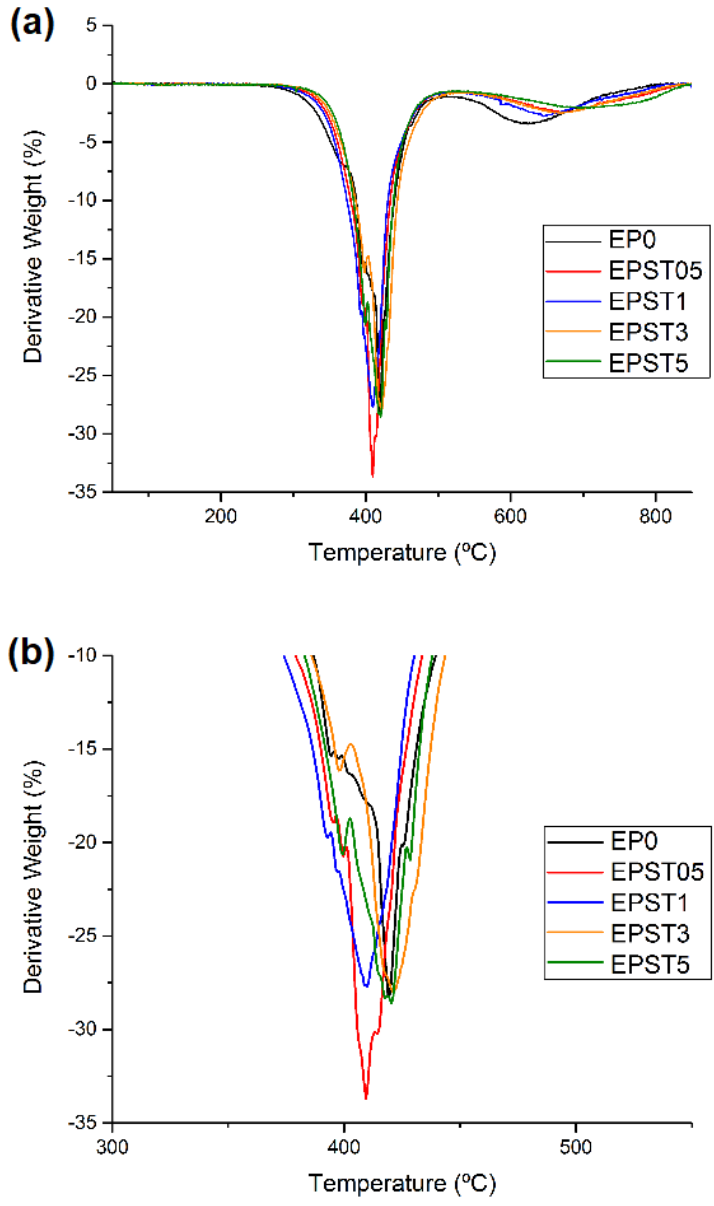

FIG. 15. Derivative traces of EP0 and EPST: (a) whole; (b) zooming in to the temperature range at the maximum rate of decomposition.

\subsection{DSC Experiment}

The DSC traces and glass transition temperature of EP0, EPS, EPST and EPB samples are shown and summarized in Fig. 18-21. The most representative curves of each loading, which means the glass transition temperatures of them are the closest ones to the average values of each-five-test, are plotted in Fig. 18(a), 19(a) and 20. The average $T_{\mathrm{g}}$ of each five-piece of EP0, EPS, EPST and EPB samples are shown in Fig. 18(b), 19(b) and 21.

The glass transition temperature of a polymer system depends on various factors, including changes of the molecular weight, chain segment mobility, density of crosslinking, and the amount of reaction residue acting as a plasticiser [24]. In this project, the ingredients and curing conditions of the nanocomposites were the same for all the samples. Thus, it is possible to make sure the changes in $T_{\mathrm{g}}$ are mainly due to the different loading concentrations, properties of the fillers and their influences upon the base material. It is obvious that the $T_{\mathrm{g}}$ of epoxy nanocomposites is overall lower than that of EP0 and decreases with the growth of filler loading concentrations, though EPB5 shows an enhancement of $T_{\mathrm{g}}$. This phenomenon should be, first, due to the lower cross-linking density of epoxy nanocomposites $[5,9,25]$.
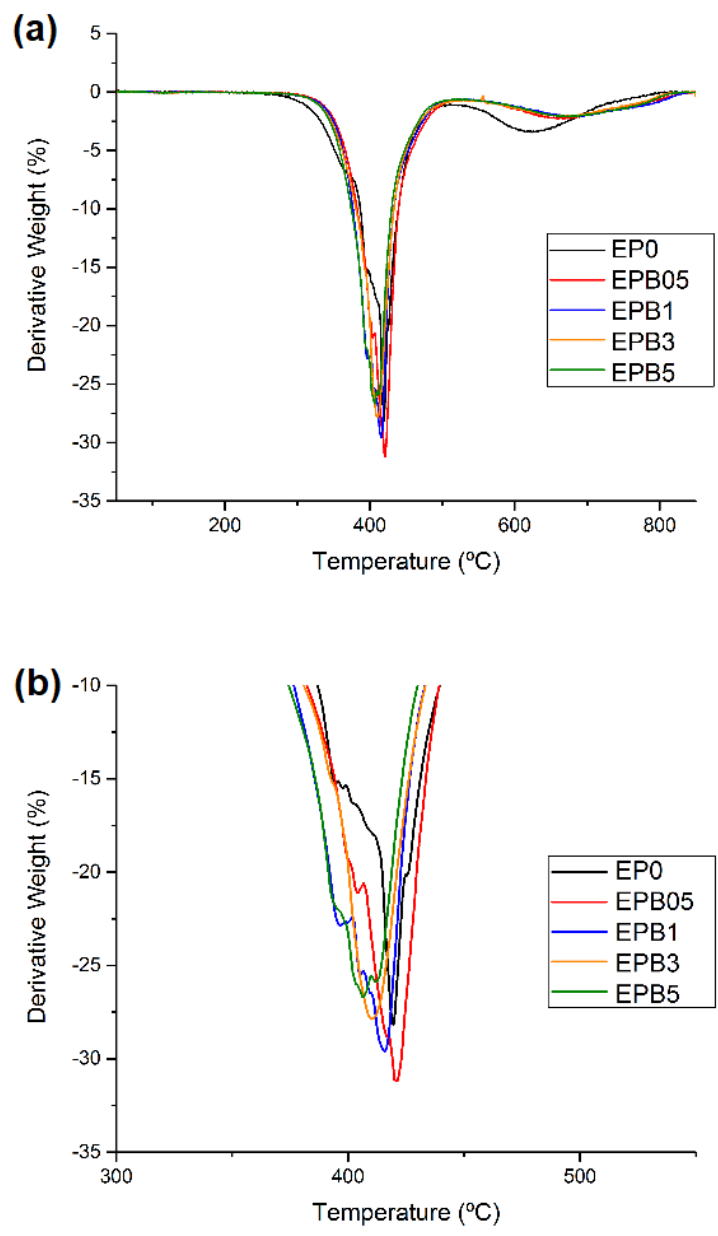

FIG. 16. Derivative traces of EP0 and EPB: (a) whole; (b) zooming in to the temperature range at the maximum rate of decomposition.

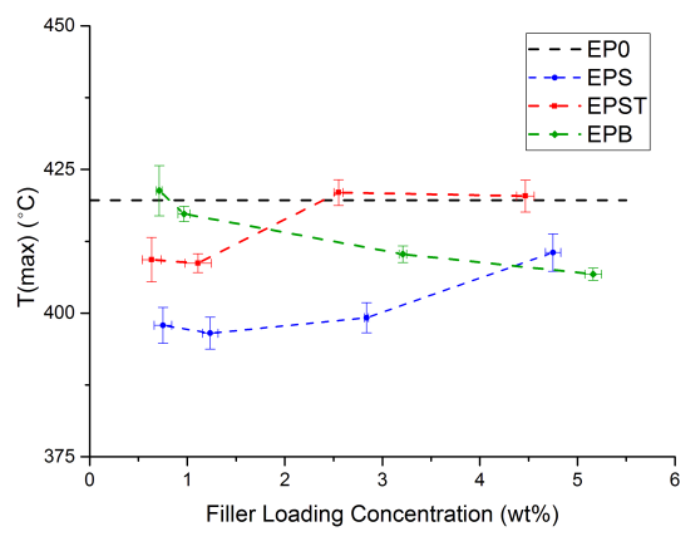

FIG. 17. Comparison of $\mathrm{T}_{\max }$ of EP0, EPS, EPST and EPB samples in different loading concentrations. 

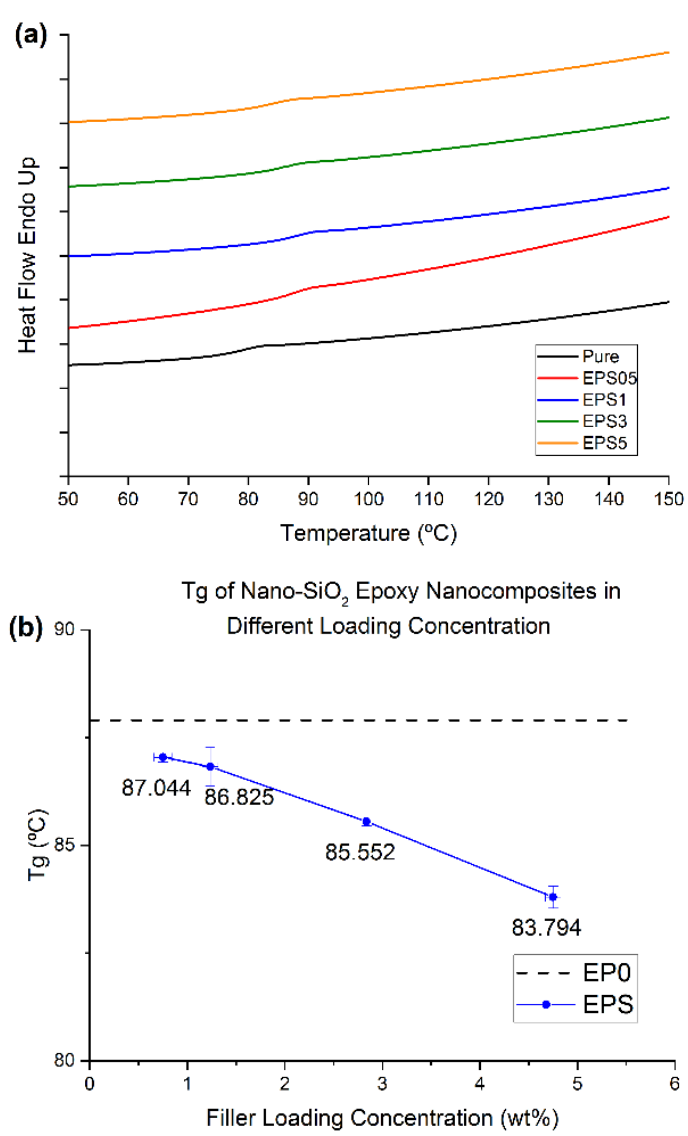

FIG. 18. (a) DSC traces of EP0 and EPS samples; (b) Average $T_{\mathrm{g}}$ of EPS samples, in different filler loading concentrations.

Second, the surface characteristics of nanoparticles and the interfacial region between the polymer matrix and nanofillers can be used to explain the behaviours of $T_{\mathrm{g}}$. Early studies indicated that the interfacial region was the most critical factor that influenced the $T_{\mathrm{g}}$ of polymer nanocomposites by Starr et al. [26, 27]. Santanu and Thomas then introduced the Dual Layer Model to explain the behaviours of $T_{\mathrm{g}}[26,27]$. In this model, the interfacial region around the nanofillers is divided into a tightly and loosely bound layer. The tightly bound region is the inner layer and it is tightly bound between nanoparticles and polymer chains by weak hydrogen bonds and thus limits the movements of the chains, which could increase the $T_{\mathrm{g}}$. However, as the surface treatment of EPST samples is not suitable, there is no tightly bound chain and this results in higher mobility of chains in the interfacial areas. Thus, the $T_{\mathrm{g}}$ of EPST samples is lower than that of EPS. With the increase in filler loadings, the volume fraction of the interfacial area between the $T_{\mathrm{g}}$ matrix and particles increases significantly, especially the loosely bound layer where free volumes are more likely to locate, and this leads to the increase in free volume and the further reduction of $T_{\mathrm{g}}$ [27-29]. This has also been observed in $[30,31]$.

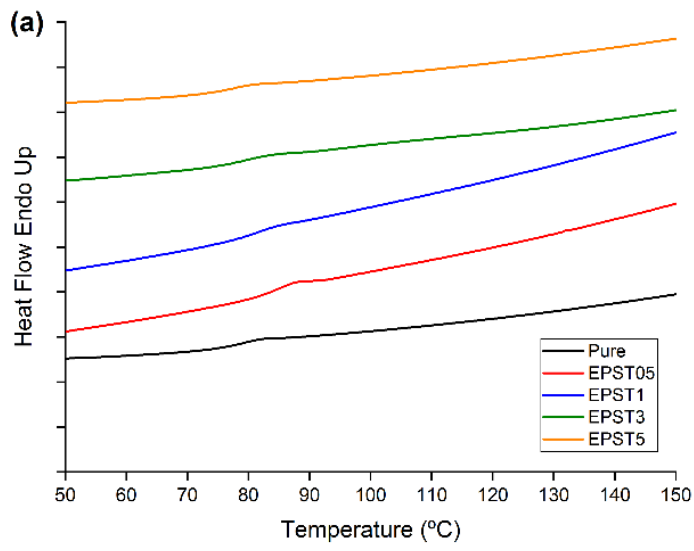

$\mathrm{Tg}$ of $\mathrm{C} 8$ Treated Nano-SiO,

(b) 90 Epoxy Nanocomposites in Different Loading Concentration

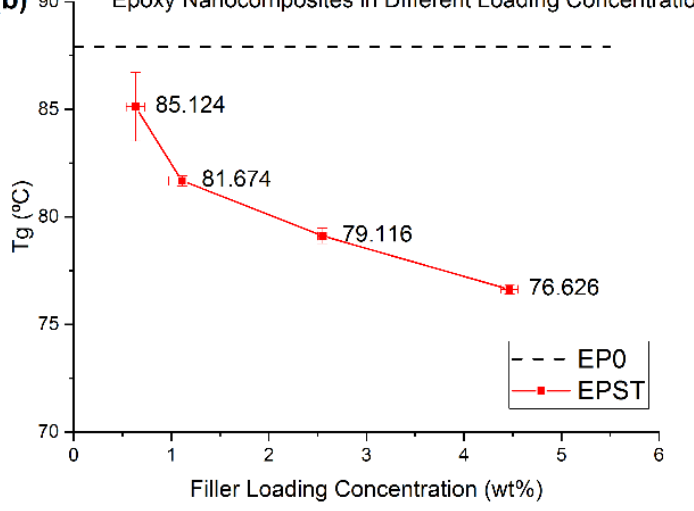

FIG. 19. (a) DSC traces of EP0 and EPST samples; (b) Average $T_{\mathrm{g}}$ of EPST samples, in different filler loading concentrations.

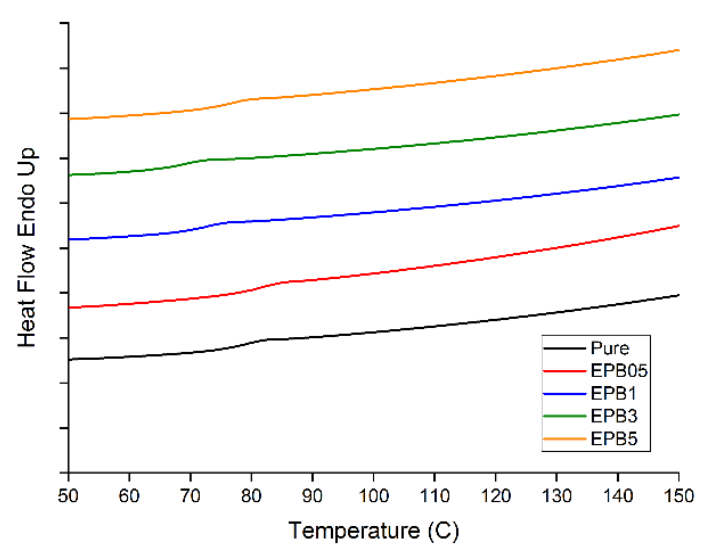

FIG. 20. DSC traces of EP0 and EPB samples.

Regarding the EPB samples, the obvious lower value of $T_{\mathrm{g}}$ than pure and silica-based composites should be mainly due to the significant low cross-linking density of curing, which should become worse with the increase in filler loadings. Moreover, the higher thermal conductivity of hBN could play a role as well. However, it is noticed there is a smaller reduction of $T_{\mathrm{g}}$ in EPB3 and even increase in EPB5. This 
should be due to a mix of the exfoliated and intercalated macroscopic layer structures of hBN-based nanocomposites [32-34] as shown in Fig. 22 which would impair the mobility of chain segments in the vicinity of particles, and thus increase the glass transition temperature [25, 35].

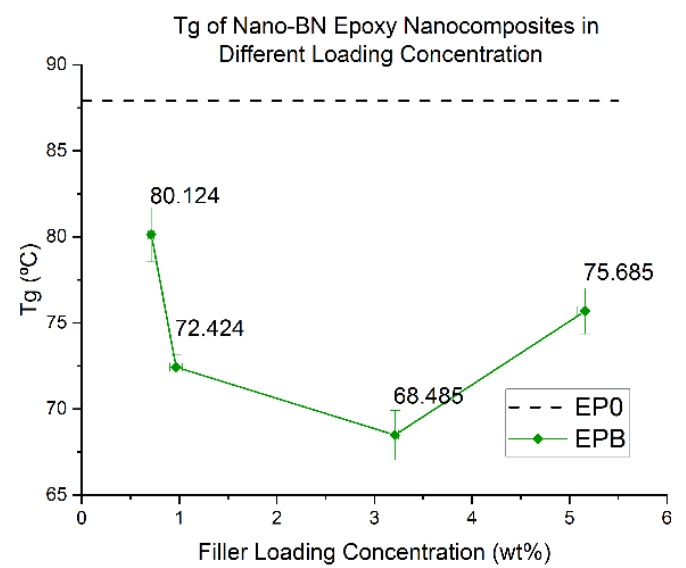

FIG. 21. Average $T_{\mathrm{g}}$ of EPB samples, in different filler loading concentrations.

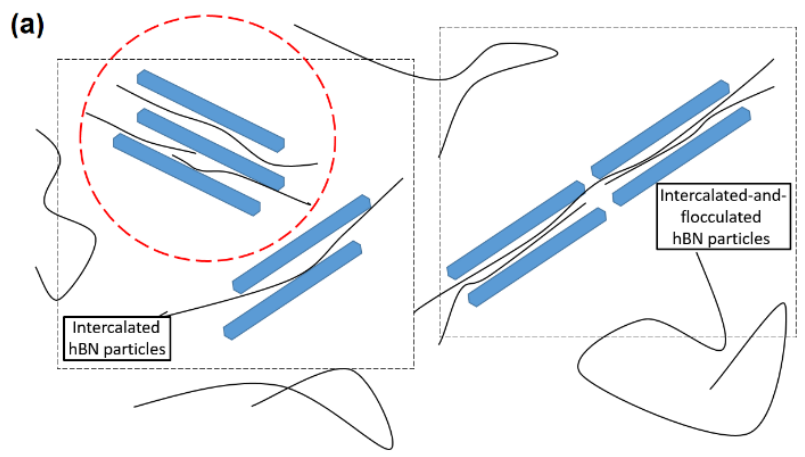

(b)

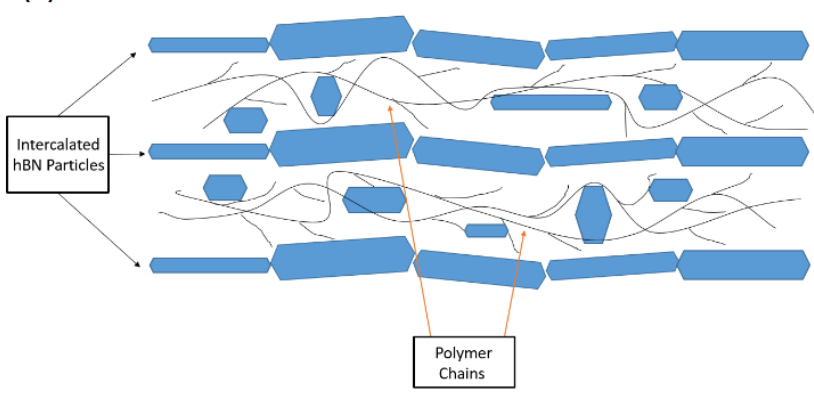

FIG. 22. (a) Illustration of exfoliated and intercalated macroscopic layer structures of hBN-based epoxy nanocomposites; (b) structure of circled area in (a).

\section{Conclusions}

According to the present work, the chemical structures and thermal properties of epoxy and its nanocomposites were investigated by TGA and DSC measurements, and the following conclusions can be made:
- The presence of nano-SiO $\mathrm{S}_{2}$ and $\mathrm{hBN}$ particles both led to the decrease in cross-linking density during curing of epoxy resins and further resulted in worse thermal stability than pure samples. However, particles acted as flame retardants for polymers and postponed the initiation of decomposition by hindering/slowing the oxidisation.

- When compared within two $\mathrm{SiO}_{2}$-based samples, surface treatment modified the cross-linking density in the interfacial areas by getting rid of some surface groups, like hydroxyl groups found in EPS samples, but unsuitable surface treatment led to the higher mobility of chain segments at the interface and thus the reduction of $T_{\mathrm{g}}$ in EPST samples.

- The morphology of EPB samples had a significant impact on its thermal properties: in TGA measurement, shorter chains resulted in improved performance when decomposing, while in the DSC measurement, exfoliated and intercalated macroscopic layer structures of hBNbased nanocomposites, which was observed in morphology characterisation by SEM, restricted the mobility of chain segments in the vicinity of particles and led to the increase in $T_{\mathrm{g}}$ in samples with higher filler loadings.

- The cross-linking density of samples should mainly affect the results of TGA, whereas the mobility of chain segments played the main role in influencing the glass transition temperature of polymer composites.

\section{References}

[1] Hedrick J L, Yilgör I, Wilkes G L, and McGrath J E 1985 Polymer Bulletin 13 201-208

[2] Gao C 2001 Journal of Jiangsu University of Science and Technology 22 63-70

[3] Dakin T W 1974 IEEE Transactions on Electrical Insulation EI-9 121-128

[4] Andritsch T, Delft University of Technology, 2010.

[5] Gu A and Liang G 2003 Polymer Degradation and Stability 80 383-391

[6] Modesti M, Lorenzetti A, Bon D, and Besco S 2006 Polymer Degradation and Stability 91 672-680

[7] Kumar A P, Depan D, Tomer N S, and Singh R P 2009 Progress in polymer science 34 479-515

[8] Tarrío-Saavedra J, López-Beceiro J, Naya S, and Artiaga R 2008 Polymer Degradation and Stability 93 2133-2137

[9] Luo Q, Li Y, Pan L, Song L, Wu L, and Lu S 2016

Journal of materials science $\mathbf{5 1}$ 8888-8899

[10] Gu J, Zhang Q, Dang J, and Xie C 2012 Polymers for Advanced Technologies 23 1025-1028

[11] Yung K and Liem H 2007 Journal of Applied Polymer Science $1063587-3591$

[12] Yu J, Huang X, Wu C, Wu X, Wang G, and Jiang P 2012 Polymer 53 471-480

[13] Lau K Y, 2013, PhD Thesis, University of Southampton.

[14] Reading M, Xu Z, Vaughan A S, and Lewin P L 2011 in Electrical Insulation Conference (EIC) 493-497.

[15] Qiang D, Wang Y, Chen G and Andritsch T 2018 IET Nanodielectrics 1 48-59.

[16] Saha M et al. 2015 Composite Interfaces 22 611-627 
[17] Liu Y-L, Wei W-L, Hsu K-Y, and Ho W-H 2004

Thermochimica Acta 412 139-147

[18] Macan J, Brnardić I, Orlić S, Ivanković H, and Ivanković M 2006 Polymer Degradation and Stability 91 122-127

[19] Park S-J, Kim H-C, Lee H-I, and Suh D-H 2001 Macromolecules 34 7573-7575

[20] Liu Y-L, Hsu C-Y, Wei W-L, and Jeng R-J 2003 Polymer 44 5159-5167

[21] Preghenella M, Pegoretti A, and Migliaresi C 2005 Polymer 46 12065-12072

[22] Jin-Cheng Z et al. 2016 2D Materials 3011004

[23] Lines M. 2001. Silica - Silicon Dioxide $\left(\mathrm{SiO}_{2}\right)$. Available at: https://www.azom.com/article.aspx?ArticleID=1114

[24] Sun Y, Zhang Z, Moon K-S, and Wong C P 2004 Journal of Polymer Science Part B: Polymer Physics 42 38493858

[25] Corcione C E and Frigione M 2012 Materials 5 29602980

[26] Starr F W, Schrøder T B, and Glotzer S C 2001 Physical Review E 64021802

[27] Lewis T J in Proceedings of the 2004 IEEE International Conference on Solid Dielectrics (ICSD) 2 792-795.

[28] Ash B J, Schadler L S, and Siegel R W 2002 Materials Letters 55 83-87

[29] Tsagaropoulos G and Eisenberg A 1995 Macromolecules 28 6067-6077

[30] Mayes A M 2005 Nature Materials 4651

[31] Nelson J K and Hu Y in Proceedings of the 2004 IEEE International Conference on Solid Dielectrics (ICSD) 2 832-835.

[32] Lin Z, Liu Y, Moon K-s, and Wong C-P in Electronic Components and Technology Conference (ECTC), 2013 IEEE 63rd 1692-1696.

[33] Lin Z, Liu Y, Raghavan S, Moon K-s, Sitaraman S K, and Wong C-p 2013 ACS applied materials \& interfaces 5 7633-7640

[34] Shen H, Cai C, Guo J, Qian Z, Zhao N, and Xu J 2016 RSC Advances 6 16489-16494

[35] Esposito Corcione C, Mensitieri G, and Maffezzoli A 2009 Polymer Engineering \& Science 49 1708-1718 